\title{
When and how should we treat cesarean scar defect — isthmocoele?
}

\author{
Konrad Futyma, Krzysztof Gałczyński, Katarzyna Romanek, Aleksandra Filipczak, \\ Tomasz Rechberger \\ $2^{\text {nd }}$ Department of Gynecology, Medical University of Lublin, Poland
}

\begin{abstract}
The reported number of cesarean sections in Poland is approximately $30 \%$ and is associated with increasing number of early and late complications. The myometrial discontinuity at the site of previous cesarean section is known in the literature as "isthmocoele", "niche", "pouch" or cesarean scar defect. In most cases presence of isthmocoele has no clinical significance, but in some patients it may cause abnormal uterine bleeding, dysmenorrhea, dyspareunia, pelvic pain or be associated with secondary infertility. This defect may be treated by laparoscopy, hysteroscopy or vaginal surgery.
\end{abstract}

Key words: cesarean scar defect, isthmocoele, niche, pouch, cesarean section

Ginekologia Polska 2016; 87, 9: 664-668

\section{INTRODUCTION}

The reported number of cesarean sections in Poland is approximately $30 \%$ and according to the data from Polish Central Statistical Office there were 124000 cesarean sections made in 2008 (30.5\% all deliveries) and 132000 in 2009 (32.2\%). Increasing number of these procedures is inseparably connected with rising number of intra- and postsurgical complications. Uterine scar dehiscence after caesarean section is described in the literature as "isthmocoele", "niche", "pouch" or "cesarean scar defect" (CSD) [1]. Fortunately, in most cases it is asymptomatic but sometimes it may be a cause of symptoms, which may decrease quality of life and cause secondary infertility. In this paper we are presenting the symptoms, diagnostic methods and modes of uterine caesarean scar defect treatment.

\section{HISTORY}

In 1911 Cameron published a case report of pregnant women who died due to rupture of uterus in the myometrial scar after caesarean section. Post-mortem examination revealed presence of uterine scar dehiscence, uterine cavity filled with blood and the fetus inside unruptured membranes in the abdominal cavity [2]. It was the first case of late complication caused by uterine scar defect. Later on, in 1924 James Hendry compared changes of uterine scars after sagittal and low, transverse incision of the uterus [3]. He found that classical, sagittal incision predisposes to abdominal adhesions formation, which cause difficult access to the uterus in case of next surgery, increases blood loss and tension of myometrium in the scar area. Moreover, he gave the precise description of previously incised myometrial tissue. The scar after transverse incision, on the other hand, was much thinner and did not cause peritoneal adhesions in most cases. Histological changes of healing myometrium were described by Jan Wojdecki and Adam Grynsztajn and published in 1970 in American Journal of Obstetrics \& Gynecology [4]. They presented the case of 31 years old women who had hysterectomy due to massive hemorrhage 18 days after caesarean section. During histological evaluation of the myometrial tissue which surrounded previous uterine incision, they found necrotic muscular fibers, granuloma, fibroblasts, fibrocytes and fibrous tissue. Morris was the next who published, in 1995, the results of histologic studies on myometrial scar. He examined tissues excised from 51 patients after hysterectomy due to uterine bleeding, in which the caesarean section was performed in the past, and found dysmorphic connective tissue involved in myometrial scar forming. 


\section{SYMPTOMS}

The main reasons for seeking medical advice of non-pregnant women are abnormal uterine bleeding, painful menstruation, pelvic pain, dyspareunia and infertility. There were some reports suggesting that it might also impair urinary bladder function but it was not finally proven $[6,7]$. Bleeding or spotting after menstruation decreases the fertility due to changes in follicular-phase mucus quality, decreasing sperm motility in cervical canal or inhibiting implantation process [8]. Abnormal uterine spotting is probably caused by impaired contractility of muscle fibers surrounding the niche $[5,9]$.

Presence of myometrial scar in the uterus of women planning to become pregnant is related to higher risk of complications such as: cesarean scar pregnancy, placenta previa, accreta, increta or percreta, scar dehiscence or rupture of the uterus $[10,11]$. Despite the fact that the CSD is ultrasonographically found in almost $50 \%$ of patients, the risk of rupture during next pregnancy does not exceeds $2 \%$. When the scar thickness is less than $50 \%$ of surrounding myometrium, this risk increases to $5 \%$. Thus ultrasonographic evaluation of scar thickness should not be used as prognostic marker of uterus rupture $[12,13]$. Downes and coworkers retrospectively analyzed 27000 of pregnancies of which $82 \%(n=22142)$ of patients delivered, $14.6 \%$ ( $n=3931$ ) had caesarean section done during the second stage of labor and $3.4 \%$ of patients underwent elective caesarean section. They found that the risk of placenta previa was as high as $0.24 \%$ in natural delivery group, $0,38 \%$ in intrapartum caesarean section group and $0.98 \%$ in elective procedure group, respectively. The risk of placenta previa was 2,5 times higher in patients who had elective procedure compared to vaginal delivery group (OR 2.62; 95\% Cl). What's interesting, there is no such relation between vaginal delivery and intrapartum caesarean section groups (OR 1.22; $95 \% \mathrm{Cl}$ [14]. Furthermore, Gilliam et al. found that the risk of placenta previa is 1,5 times higher after caesarean section than in case of vaginal delivery (OR 1.59, 95\% Cl) and it rises with the number of procedures performed in single patient. Interestingly, the highest risk was observed in women who delivered vaginally and caesarean section was performed in next pregnancy (OR $8.76(95 \% \mathrm{Cl})$ [15].

Placenta increta is also known complication that occurs more often after caesarean section in previous pregnancy. Bowman et al. published retrospective analysis of more than 70000 patients who had caesarean section performed and found that only $0,27 \%(n=196)$ of them had placenta increta during following pregnancy [16]. Also, in this case, the risk was rising with the number of previous caesarean sections and was as high as $4.9(95 \% \mathrm{Cl}$ 1.7-14.3) and 7.7 (95\% $\mathrm{Cl} 2.4-24.9)$ after 2 and 3 procedures, respectively. Moreover, the authors did not find any other factors influencing on this complication frequency, what was previously reported [17].

\section{ETIOPATHOGENESIS}

Vervoort et al. postulated four different hypotheses on cause of isthmocoele. First, concerns the location of the incision that was made too low in the cervical part of uterus, that contains mucous glands. Mucus produced in the time of wound healing may dilate the sutured edges of the myometrial tissue [18]. The confirmation for this theory was the study which stated that isthmocoele was found more frequently in patients who had caesarean section performed on maximal dilation, when finding proper place between uterus and cervix is more difficult [19]. The second cause may be improper wound suturing, without all layers of myometrium, which is often when decidual layer saving technique is used. In contrast, Roberge and colleagues analyzed suturing techniques described in the literature, and did not find any correlation with isthmocoele frequency. The third hypothesis is a suspicion that the early adhesions between the myometrial wound and anterior abdominal wall might be the factor that increases the risk of developing isthmocoele. It based on the fact that those adhesions pull the edges of the wound thus impairing healing process. This situation may be even more obvious in retroflexed uterus, because in this patients isthmocoele is usually bigger. The risk of scar thickness of less than $50 \%$ of surrounding myometrium is twice higher than in anteflexed uterus. Explanation for this dependency is the fact that anterior uterine wall stretching forces are mainly focused in the point of uterine axle flexion what probably decreases blood flow in healing tissues. This is in agreement with fourth hypothesis which highlights impaired perfusion and hypoxia as main cause of isthmocoele. The production of collagen is decreased thus prolonging the healing time. The authors also state that it may be the reason for recurrence of isthmocoele in $5 \%$ of patients after repairing surgery $[20,21]$. There are some other theories involving obesity as a risk factor, but the mechanism of action is unknown $[18,22]$

\section{DIAGNOSIS}

Isthmocoele is usually found in ultrasound imagining and it is described as anechoic triangular space or niche or even hyperechoic endometrium (Figs. 1 and 2) [5, 23]. Van der Voet et al. examined 263 women after caesarean section with ultrasound alone or ultrasound with gel instillation (GIS, Gel Instilation Sonography) and found niche in 49.6\% and $64.5 \%$ of them, respectively [24]. Moreover, the space was bigger and scar thickness was smaller during GIS comparing to ultrasound only. They also found that in women whose scar thickness was smaller than $50 \%$ of myometrium, 


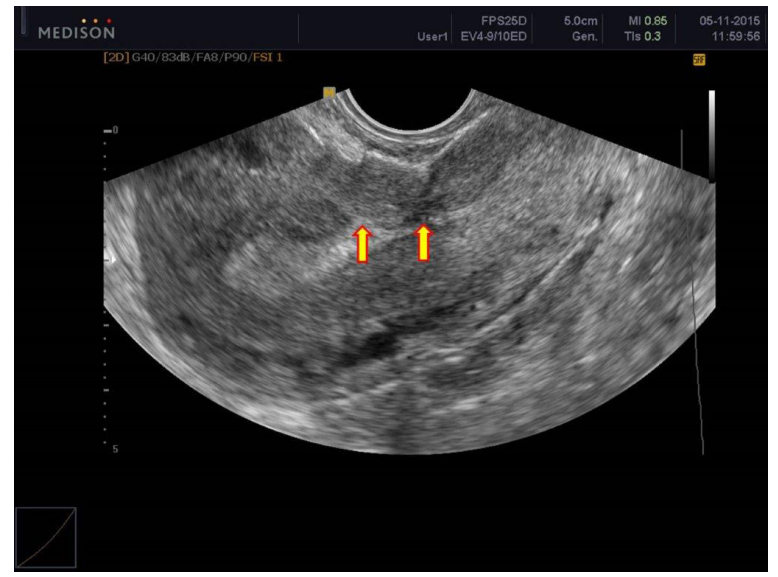

Figure 1. Ultrasound image of uterus of the patient after three cesarean sections. Arrows point two scars in the myometrium

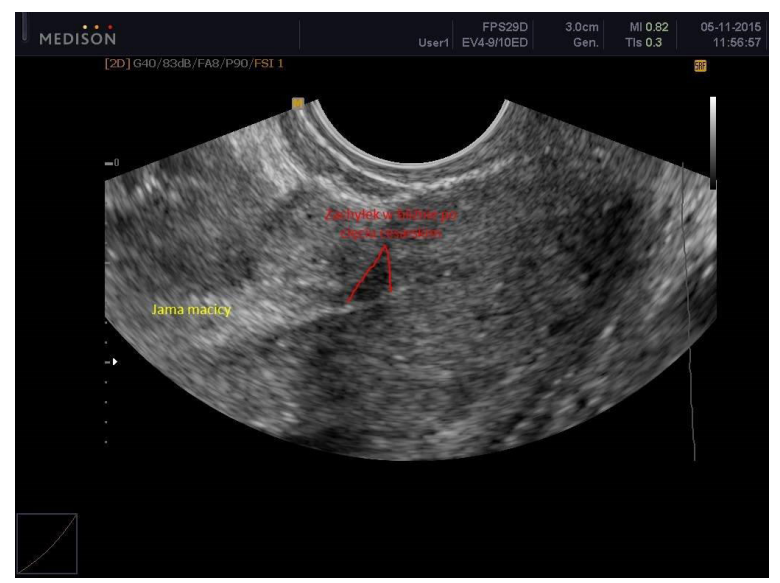

Figure 2. Ultrasound image of the uterus. Hypoechoic defect in the anterior uterine muscle attributable to prior cesarean section

the risk of abnormal uterine bleeding was 6 times higher than in others (OR 6.13,95\% Cl 1.74-21.63). The scar defect was also confirmed by hysteroscopy and described as "cleft" in anterior uterine wall, just above the cervical canal by Fabres et al. [1]. They also concluded that ultrasound will be the most useful during abnormal uterine bleeding episode in the diagnosing of isthmocoele. In some patients with scar defect they aspirated with the teflon catheter brownish discharge. After this procedure spotting resolved and ultrasound did not revealed the niche.

The other method of diagnosing the scar defect is hysterosalpingography (HSG) (Fig. 3). It is performed usually in patients with impaired fertility in order to diagnose any anatomical changes in uterine cavity and oviducts. In the study by Surapaneni i Silberzweig 148 patients were examined with HSG due to secondary infertility after caesarean section. The scar defect was found in $60 \%(n=89)$ patients, including 58 patients with focal outpouchings, and 31 patients with thin linear defects. Additionally, in 48 (54\%) patients the diverticula were located at the lower uterine cavity, in

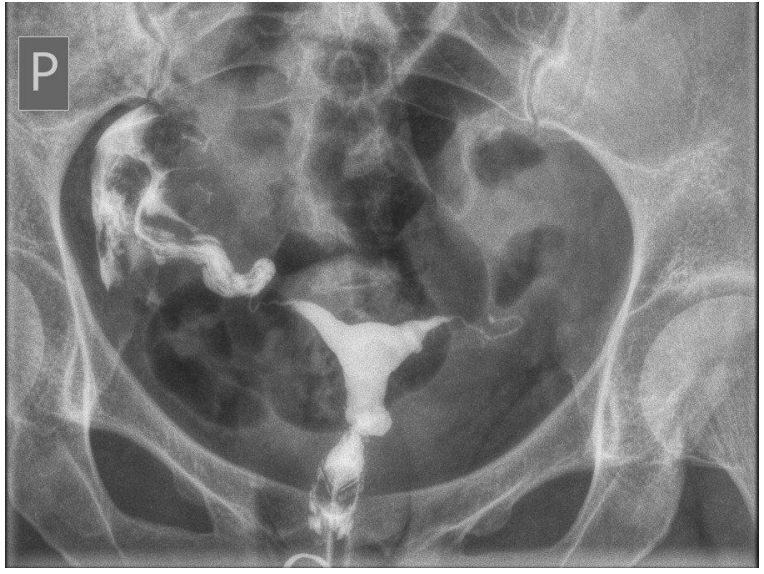

Figure 3. Hysterosalpingogram in 39-year-old patient after cesarean section and ectopic pregnancy in the left fallopian tube with isthmocoele at the level of uterine isthmus

$32(36 \%)$ at the uterine isthmus, and in nine cases (10\%) at the upper endocervical canal [25].

\section{PHARMACOLOGICAL TREATMENT}

In case of caesarean scar defect surgical treatment is usually applied. In PubMed database we have found only one preliminary report concerning pharmacological treatment for abnormal uterine bleeding caused by caesarean scar defect, published to date. Tahara et al. prescribed oral contraception $(0.5 \mathrm{mg}$ norgestrel and $0.05 \mathrm{mg}$ ethinylestradiol) for 11 women with CSD for 3 months. Then, the patients were followed-up for 6 months. In all cases the size of niche decreased as well as vascularization of scar region in color Doppler scanning [26]. The therapeutic effect of steroid hormones on vascular malformations was previously presented and is probably caused by endothelium function improvement [27].

\section{SURGICAL TREATMENT \\ - VAGINAL APPROACH}

The literature describing surgical methods of caesarean scar defect treatment is vast. Vaginal approach can be used to excise the scar and isthmocoele. During surgery bladder must be dissected away from uterine cervix until the scar is reached. In study by Luo et al. 42 patients received vaginal intervention and the wound after scar excision was sutured with 2 layer absorbable thread. Mean time of the procedure was 60 minutes (30-90 minutes) and mean hospitalization was 3 days. During long time follow-up resolution of bothersome symptoms was achieved in 93\% of patients [28]. This approach was also used by Chen and colleagues in 64 women. They additionally injected adrenaline $0.3 \mathrm{mg}$ in $500 \mathrm{~mL}$ of $0.9 \%$ saline) submucusally in order to decrease bleeding and dissect the bladder from the cervix. The wound was closed with continuous 2-0 suture. Then, the patients 
were followed-up for 6 months and first ultrasound was performed a month after procedure. Abnormal uterine bleeding resolved in $86 \%$ but the authors do not describe the scar after the procedure [29].

\section{SURGICAL TREATMENT — HYSTEROSCOPY}

Alternative method is hysteroscopic resection of scar tissue from the isthmocoele region and coagulation of hypervascularised tissue. Chang et al. used this technique in 22 patients and the symptoms resolved in 14 (63\%) and significantly decreased in the rest of them [30]. In another paper published in 2008 , hysteroscopic roller-ball coagulation of scar tissue was used in 26 patients. In all of them abnormal bleeding was the indication for surgical treatment and in 9 patients additionally the secondary infertility was diagnosed. In all patients abnormal bleeding resolved and 8 out of 9 infertile patients became pregnant [31]. Hysteroscopy, as minimally invasive surgical method which should be applied as first line treatment, was used also in another study in 120 patients with symptomatic isthmocoele. In $80 \%$ of patients symptoms resolved completely, in 7\% decrease and in $13 \%$ severity of symptoms did not changed [32].

\section{SURGICAL TREATMENT — LAPAROSCOPY}

In 2008 the results of laparoscopic intervention due to large myometrial scar defect in 3 patients were published. The defect concerned total thickness of myometrium and the scar was covered only by the peritoneum. The $\mathrm{CO}_{2}$ laser was used in order to excise the edges of scary tissue precisely. Than the Hegar probe was introduced in cervical canal to preserve the continuity of the cervical canal with the uterine cavity. Then the wound was sutured with 2-0 absorbable sutures and covered with peritoneum. MRI imagining 3 month after the procedure revealed the level of previous scar normal myometrium with thickness of even $11.0 \mathrm{~mm}$. One of those patients become pregnant and no dehiscence was observed in the lower uterine segment during caesarean section. The authors conclude that in case of deep and wide defects, involving total myometrial thickness, laparoscopic excision should be used as effective procedure [33]. The same method was used in another 13 patients of which 4 became pregnant and in all cases MRI scanning revealed no changes in lower uterine segment. It is postulated that this approach of repairing caesarean scar should be administered only in patients with defect of full myometrial thickness in centers experienced in advanced laparoscopic techniques.

Physicians from another center in USA made one step further and described the case of patient with scar defect symptoms in which robotic surgery was performed. Using monopolar coagulation, scar tissue was removed and the myometrium was sutured with 0-0 Vicryl in two layers. Three months later on follow-up visit patient did not reported any complains which were the indication for surgical treatment [35]. There are some other reports on successful robotic restoration of defects in lower segments of uterus after caesarean section, however this data is limited probably due to high costs of this procedure.

\section{CONCLUSIONS}

Caesarean scar defect can be the cause of symptoms decreasing comfort and quality of life of affected women. When counseling those patients, with abnormal uterine bleedings, pain, and infertility we have to remember that isthmocoele might be the reason of those complains.

\section{PRACTICAL ISSUES}

1. Asymptomatic isthmocoele should not be an indication for any surgical procedure.

2. Only bothering symptoms caused by uterine scar defect can justify the risk of surgical intervention.

\section{REFERENCES}

1. Fabres C, Aviels G, De La Jara C, [et al.]. The cesarean delivery scar pouch. Clinical implications and diagnostic correlation between transvaginal sonography and hysteroscopy. J Ultrasound Med. 2003, 22, 695-700.

2. Cameron SJ. Gravid Uterus ruptured through the Scar of a Caesarean Section. Proc R Soc Med. 1911, 4, 147-149.

3. Hendry J. Observations made at "Repeat" Caesarean Sections on the Uterine Scar where the Previous Incision had been made through the Upper Contractile Part of the Uterus and where the Previous Incision had been made through the Lower Non-Contractile Part or Lower Uterine Segment. Proc R Soc Med. 1924, 17, 156-163.

4. Wojdecki J, Grynsztajn A. Scar formation in the uterus after cesarean section. Am J Obstet Gynecol. 1970, 107, 322-324.

5. Morris H. Surgical pathology of the lower uterine segment caesarean section scar: is the scar a source of clinical symptoms? Int J Gynecol Pathol. 1995, 14, 16-20.

6. Fabres C, Aviles G, De La Jara C, [et al.]. The cesarean delivery scar pouch: clinical implications and diagnostic correlation between transvaginal sonography and hysteroscopy. J Ultrasound Med. 2003, 22, 695-700.

7. Bij de Vaate AJM, Brolmann HAM, van der Voet LF, [et al.]. Ultrasound evaluation of the caesarean scar: relation between a niche and postmenstrual spotting. Ultrasound Obstet Gynecol. 2011, 37, 93-99.

8. Florio P, Filippeschi M, Moncini I, [et al.]. Hysteroscopic treatment of the cesarean-induced isthmocoele in restoring infertility. Curr Opin Obstet Gynecol. 2012, 24, 180-186.

9. Thurmond AS, Harvey WJ, Smith SS. Cesarean section scar as a cause of abnormal vaginal bleeding: diagnosis by sonohysterography. $J$ Ultrasound Med. 1999, 18, 13-16.

10. Zimmer M, Pomorski M, Fuchs T, [et al.]. Ultrasonographic analysis of cesarean scars features in nonpregnant uterus. Ginekol Pol. 2007, 78, 842-846.

11. Miller ES, Hahn K, Grobman WA. Society for Maternal-Fetal Medicine Health Policy Committee. Consequences of a primary elective cesarean delivery across the reproductive life. Obstet Gynecol. 2013, 121, 789-797.

12. Regnard C, Nosbusch M, Fellemans C, [et al.]. Cesarean section scar evaluation by saline contrast sonohysterography. Ultrasound Obstet Gynecol. 2004, 23, 289-292.

13. Ofili-Yebovi D, Ben-Nagi J, Sawyer E, [et al.]. Deficient lower-segment Cesarean section scars: prevalence and risk factors. Ultrasound Obstet Gynecol. 2008, 31, 72-77.

14. Downes KL, Hinkle SN, Sjaarda LA, [et al.]. Previous prelabor or intrapartum cesarean delivery and risk of placenta previa. Am J Obstet Gynecol. 2015, 212, 669.e1-669.e6.

15. Gilliam M, Rosenberg D, Davis F. The likelihood of placenta previa with greater number of cesarean deliveries and higher parity. Obstet Gynecol. 2002, 99, 976-980. 
16. Bowman ZS, Eller AG, Bardsley TR, [et al.]. Risk factors for placenta accreta: a large prospective cohort. Am J Perinatol. 2014, 31, 799-804.

17. Cieminski A, Długołiecki F. Placenta previa accreta. Ginekol Pol. 2004, 75, 919-925.

18. Vervoort A, Uittenbogaard L, Hehenkamp W, [et al.]. Why do niches develop in Caesarean uterine scars? Hypotheses on aetiology of niche development. Hum Reprod. 2015, 1-8.

19. Osser OV, Jokubkiene L, Valentin L. Cesarean section scar defects: agreement between transvaginal sonographic findings with and without saline contrast enhancement. Ultrasound Obstet Gynecol. 2010, 35, 75-83.

20. Alison M. Repair and regenerative processes. In: O'D McGee J, Isaacson PG, Wright NA, [et al.]. (eds.). Oxford textbook of pathology. Vol. 1: Principles of Pathology, New York, 1992, 377-378.

21. Osser O, Jokubkiene L, Valentin L. High prevalance of defects in Cesarean section scars at transvaginal ultrasound examination. Ultrasound Obstet Gynecol. 2009, 34, 90-97.

22. Hayakawa H, Itakura A, Mitsui T, [et al.]. Methods for myometrium closure and other factors impacting effects on cesarean section scars of the uterine segment detected by the ultrasonography. Acta Obstet Gynecol Scand. 2006, 85, 429-434.

23. Roberge $\mathrm{S}$, Boutin $\mathrm{A}$, Chaillet $\mathrm{N}$, [et al.]. Systematic review of cesarean scar assessment in the nonpregnant state: imaging techniques and uterine scar defect. Am J Perinatol. 2012, 29, 465-471.

24. Van der Voet LF, Bij de Vaate AM, Veersema S, [et al.]. Long-term complications of caesarean section. The niche in the scar: a prospective cohort study on niche prevalence and its relation to abnormal uterine bleeding. BJOG. 2014, 121, 236-244.

25. Surapaneni K, Silberzweig JE. Cesarean section scar diverticulum: appearance on hysterosalpingography. AJRAm J Roentgenol. 2008, 190, 870-874.
26. Tahara M, Shimizu T, Shimoura H. Preliminary report of treatment with oral contraceptive pills for intermenstrual vaginal bleeding secondary to a cesarean section scar. Fertil Steril. 2006, 86, 477-479.

27. Van Cutsem E, Rutgeerts P, Vantrappen G. Treatment of bleeding gastrointestinal vascular malformations with oestrogen-progesterone. Lancet. $1990,335,953-955$

28. Luo L, Niu G, Wang Q, [et al.]. Vaginal repair of cesarean section scar diverticula. J Minim Invasive Gynecol. 2012, 19, 454-458.

29. Chen Y, Chang Y, Yao S. Transvaginal management of cesarean scar section diverticulum: a novel surgical treatment. Med Sci Monit. 2014, 20, 1395-1399.

30. Chang Y, Tsai EM, Long CY, [et al.]. Resectoscopic treatment combined with sonohysterographic evaluation of women with postmenstrual bleeding as a result of previous cesarean delivery scar defects. Am J Obstet Gynecol. 2009, 200, 370.e1-370.e4.

31. Gubbini G, Casadio P, Marra E. Resectoscopic correction of the "isthmocoele" in women with postmenstrual abnormal uterine bleeding and secondary infertility. J Minim Invasive Gynecol. 2008, 15, 172-175.

32. Raimondo G, Grifone G, Raimondo D, [et al]. Hysteroscopic treatment of symptomatic cesarean-induced isthmocoele: a prospective study. J Minim Invasive Gynecol. 2015, 22, 297-301.

33. Donnez O, Jadoul P, Squifflet J, [et al.]. Laparoscopic repair of wide and deep uterine scar dehiscence after cesarean section. Fertil Steril. 2008, 89, 974-980.

34. Marotta ML, Donnez J, Squifflet J, [et al.]. Laparoscopic repair of post-cesarean section uterine scar defects diagnosed in nonpregnant women. J Minim Invasive Gynecol. 2013, 20, 386-391.

35. La Rosa MF, McCarthy $S$, Richter $C$, [et al.]. Robotic repair of uterine dehiscence. JSLS. 2013, 17, 156-160. 